\title{
Planning for Distribution System with Grey Wolf Optimization Method
}

\author{
Muhammad Mohsin Ansari ${ }^{1,3} \cdot$ Chuangxin Guo ${ }^{1,3} \cdot$ Muhammad Suhail Shaikh ${ }^{2}$. Nitish Chopra ${ }^{4}$. Inzamamul Haq ${ }^{5}$. \\ Lingbing Shen ${ }^{6}$
}

Received: 31 July 2019 / Revised: 19 January 2020 / Accepted: 30 March 2020 / Published online: 6 May 2020

(c) The Author(s) 2020

\begin{abstract}
Nowadays Distribution generation (DG) has achieved to further precious awareness, especially inside the power system fields, so the strength and dependability specifically in the distribution system. Optimum scheduling of DG not only focuses on the size of DG only too puts a load on the optimal location of generators. Install for DG at the optimum location along with optimal size into the distribution system would improve the system performance and also give price effectual solved to the planning of the distribution network. The positive impact of optimum DG position into the distribution system would improve system voltage profile, reduction in line losses, improved power standard, make better reliability and strength of the distribution network. GWO is modeled based on the unique hunt, searching for a target, encircling target, and attacking prey, are executing to perform the optimization. The GWO is determined to the IEEE-16, 30, 57 and 118-bus test systems radial distribution network as well as considering multiplier DG units in the system. The better study outcome of the attained to without DG, with DG, type 1 DG, type 2 DG, with type 3 DG at 0.9 pf and with type DG at unity pf. Moreover, the obtained is compared as well as the net outcome of the proposed procedure for the sequence to see the efficiency and effectual and the distribution systems.
\end{abstract}

Keywords Metaheuristic techniques · Voltage profile $\cdot$ Real power loss minimization · Optimum DG location · Optimum DG size $\cdot$ Radial distribution system

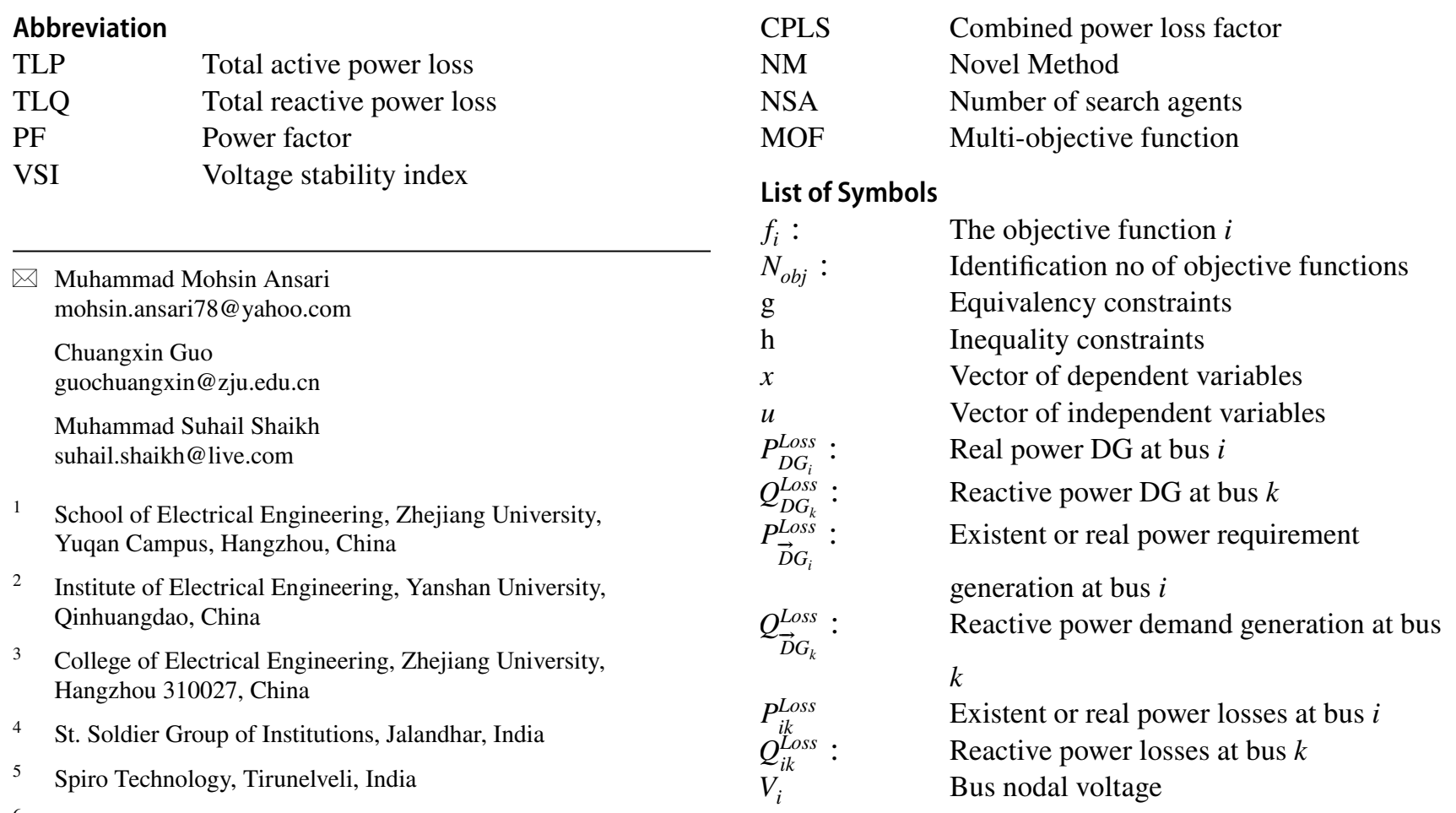

6 Zhejiang Huayun Power Engineering Design Consultation Company Limited, Hangzhou, China 


\begin{tabular}{|c|c|}
\hline$I_{i k}^{*}$ & $\begin{array}{l}\text { Phasor current magnitude flow from the } \\
\text { bus } i \text { to } k\end{array}$ \\
\hline & Voltage magnitude at bus $i$ \\
\hline$Y_{i k}:$ & $\begin{array}{l}\text { The magnitude of the } i k \text { th element in the } \\
\text { bus admittance matrix }\end{array}$ \\
\hline & Total amount of bus branches \\
\hline & Objective function power loss \\
\hline$S_{D G i}^{\text {loss }}$ Tolawerloss & Complex total power loss \\
\hline & Voltage magnitude at bus $i$ \\
\hline$P_{\vec{D} G_{i}}^{\text {Total }}:$ & $\begin{array}{l}\text { Total real power demand generation in the } \\
\text { system }\end{array}$ \\
\hline$Q_{i}:$ & Reactive power in the system $i$ \\
\hline & $\begin{array}{l}\text { The angle of the } i k \text { th element in the bus } \\
\text { admittance matrix }\end{array}$ \\
\hline & Current $i k$ th of the branch \\
\hline & Real and reactive power flow at bus $i$ and $k$ \\
\hline$P_{D, i} Q_{\vec{D}, i}$ & $\begin{array}{l}\text { Real and reactive power demands at bus } i \\
\text { and } k\end{array}$ \\
\hline$V_{i}, V_{k}$ & Voltage magnitudes at bus $i$ and $k$ \\
\hline$P_{D G, i}, Q_{D G, i}:$ & $\begin{array}{l}\text { Real and reactive power generation of DG } \\
\text { at bus } i \text { and } k\end{array}$ \\
\hline$P_{G, i}, Q_{G, i}:$ & $\begin{array}{l}\text { Real and reactive power generation at the } \\
\text { bus } I \text { and } k\end{array}$ \\
\hline$\delta_{i}, \delta_{k}$ & Voltage angles at bus $i$ and $k$ \\
\hline & $\begin{array}{l}\text { The magnitude of the } i k \text { th element in the } \\
\text { bus the admittance matrix }\end{array}$ \\
\hline
\end{tabular}

\section{Introduction}

As we know that nowadays the power generation and transmission systems are in operation under more and more emphasize state and are experiencing to rise the power loss due to increasing demand, environmental and economic or financial restriction, along with a competitor energy industry [1], so there are some needs to make better power demand, the standard of power, and preferably the growing of DG and the problems of global warming to the environment. Dispersed generation can the little or intermediate power plant installation was neighboring to the statistical distribution supply to the high voltage of electrical power transmitting and distribution to the proper of the supply to the consumer endmost [2]. The demand for energy is anticipated for the increase is $39 \%$ by 2040 [3]. To determine the optimum DG allocation optimum bus location and more size of DG units and reduced the total power loss in the distribution systems [4]. Consequently, the significant figure of the literature has dedicated to the region, along with the different method purpose the minimization of the real power system [5-11], and active power loss minimization [12-15]. Moreover, decreasing the loss of energy and better voltage profile to the distributions system has prepared the multi-objective function
(MOF) $[16,17]$. In the difference imaginary power losses, the consciousness. More advantages connected as well as improved the reactive power. As long as the decrease imaginary power consumption and the upgrade system, voltage drop, increase network load capacity and the assistance to the transmission line.

The author has been considered condition minimizations of reactive power losses in the single objective functions [18-20]. The use of meta-heuristic procedures is solving to the DG allocation difficulty termination the analytical and classical approach. Different methods are artificial bee colony algorithm (ABC) [21], gravitational search algorithm (GSA) [22], bat optimization algorithm (BAT) [23], particle swarm optimization (PSO) as well as constriction factor approach [24], flower pollution algorithm (FPA) [25], modified teaching learning-based optimization (MTLBO) [26], backtracking search algorithm (BSA) [27], krill heard algorithm (KHA) [28], moth flame optimization (MFO) [29], sine cosine algorithm (SCA) [30], crow search algorithm (CSA) [31]. The procedure of optimization based on the unique hunting, searching for prey, encircling prey, and attacking prey of grey wolf optimization's is applied to find the optimum location and size of DG in a power distribution network. The motive of developing as the meta-heuristic algorithms is to reduction find the place.

The main contributions of this paper are summarized

- The proposed methods that have been applied on standard IEEE-16, 30, 57 and 118 radial bus test distribution systems along considering multiplier DG power losses minimization and get a better voltage profile improvement.

- Comparison results along with type $3 \mathrm{DG}$ at $0.9 \mathrm{pf}$ and with type DG at unity pf obtained by the proposed algorithm along with the optimum location and size of DG as obtained by the GWO is more effective and voltage profile.

- The proposed algorithm is compared as well as from the VSI, CPLS and NM method given the superior solution.

The rest of the paper as per the following: Sect. 2 arrangement the problem formulation, Sect. 3 described the GWO method, Sect. 4. The detail explanation analysis and parameters of IEEE-16, 30, 57 and 118 bus distribution system percentage loss reductions and then also convergence characteristics curves respectively and finally Sect. 5 has been present in conclusion. 


\section{Result and Discussions}

The proposed algorithm has been executing by MATLAB $2015 \mathrm{a}$ and the IEEE-16, 30, 57, and 118 buses of the radial distribution system. The main aim of loss minimization has been executing using GWO, which has been valuing as well as the population is 50 , and the maximum iteration is 200 . The objective function is to decide the optimum location and size of DG in the radial distribution networks and the power loss minimization. The detail algorithm methods of working by flow chart gradually. The proposed algorithm is compared as well as from the VSI, CPLS and NM methods [35], given the superior solution.

\subsection{Problem Formulation}

The problem formulation is to define the size of DG, optimal location in the reduction of distribution network, to the active power loss in the distribution system, and the active power is produced and to the operate the DG is evaluated.

$\operatorname{minimizef}_{i}(x, u), i=1,2,3,4 \ldots N_{o b j}$,

$\operatorname{Subjecttog}(x, u)=0$,

$h(x, u) \leq 0$,

\subsection{Objective Function}

The objective function is $\left(\mathrm{I}^{2} \mathrm{R}\right)$, or system power loss minimization in the section power flow of b/w buses $k$ and $i$ at bus $k$ is given, Fig. 1, in this system the reactive power is neglected,

$$
\begin{aligned}
& S_{D G_{i}}=P_{D G_{i}}^{\text {Loss }}+j Q_{D G_{k}}^{\text {Loss }} \\
& S_{\vec{D} G_{i}}=P_{\vec{D} G_{i}}^{\text {Loss }}+j Q_{\vec{D} G_{k}}^{\text {Loss }} \\
& S_{i k}=P_{i k}^{\text {Loss }}+j Q_{i k}^{\text {Loss }}
\end{aligned}
$$

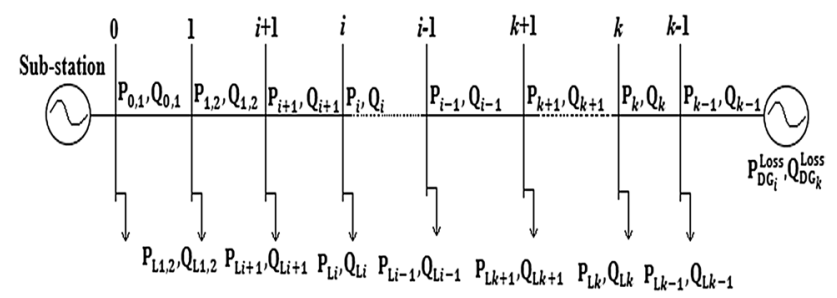

Fig. 1 Single line diagram of radial distribution system
$S_{i k}=V_{i} I_{i k}^{*}$

$S_{i k}=V_{i}\left(V_{i}^{*}-V_{k}^{*}\right) Y_{i k}+V_{i} V_{i}^{*} Y_{i k 0}$

$S_{k i}=V_{i}\left(V_{k}^{*}-V_{i}^{*}\right) Y_{k i}+V_{k} V_{k}^{*} Y_{k i 0}$

Consequently, the addition of the power flow in Eqs. (5) and (6), and the power loss system in between buses $i$ and $k$,

$S_{D G}^{\text {TotalPowerloss }}=S_{i k}+S_{k i}$

The overall in a power loss system to get along with the branches of power flow and the total power loss inside the slack bus be able to get the power flow along with sum at the finished bus,

$F_{\text {loss }}^{\text {Power }}=\operatorname{real}\left[\sum_{i=1}^{n} S_{D G}^{\text {TotalPowerloss }}\right]$

\subsection{Constraints}

They consist of voltage magnitude and true power, including DG. The variation is according to them, and they are restricted to be inside the constraints through the optimization performance. These systems are changing in the identified the following,

$V_{i}^{\min } \leq V_{i} \leq V_{i}^{\max } \forall i \varepsilon N G$

$P_{D G}^{\min } \leq P_{\vec{D} G_{i}}^{\text {Total }} \leq P_{D G}^{\max } \forall i \varepsilon N G$

$Q_{i}^{\min } \leq Q_{i} \leq Q_{i}^{\max } \forall i \varepsilon N G$

$\emptyset_{i k}^{\min } \leq \emptyset_{i k} \leq \emptyset_{i k}^{\max } \forall i \varepsilon N G$

$I_{i k}^{\min } \leq I_{i k}^{\max } \forall i \varepsilon N G$

\subsection{Equality Constraints}

The equality constraints are the stability power generations, load flow power, load demand, and power losses [33, 34],

$S_{i}=P_{i k}+j Q_{i}^{*}=V_{i} I_{i}^{*}$

$S_{i}=V_{i} \sum_{k=1}^{n} V_{k}^{*} Y_{i k}^{*}=\sum_{k=1}^{n}\left|V_{i}\right| V_{k}|| Y_{i k} \mid<\left(\delta_{i}-\delta_{k}+\emptyset_{i k}\right)$

Solve the real and imaginary parts, after then the power load flow mathematical problem without DG are given, 
$P_{i}=\sum_{k=1}^{n}\left|V_{i}\right| V_{k}|| Y_{i k} \mid \cos \left(\delta_{i}-\delta_{k}+\emptyset_{i k}\right)=P_{G, i}-P_{D, i}=0 \quad \forall i \varepsilon n b$

$Q_{i}=\sum_{k=1}^{n}\left|V_{i}\right| V_{k}|| Y_{i k} \mid \sin \left(\delta_{i}-\delta_{k}+\emptyset_{i k}\right)=Q_{G, i}-Q_{\vec{D}, i}=0 \quad \forall i \varepsilon n b$

The basic power balance equation,

$P_{G, i}=P_{D, i}+P_{L}$

$Q_{G, i}=Q_{\vec{D}, i}+Q_{L}$

The power flow losses as well as the DG the true power generation units operate in unity pf, then the mathematical problem of power flow is given.

The DG is an active power source only at unity pf, so the $Q_{D G, i}=0$,

$P_{i}+P_{D G, i}=P_{D, i}+P_{L}$

$Q_{i}=Q_{\vec{D}, i}+Q_{L}$

The last power flow mathematical problem for the distribution system,

$$
\begin{aligned}
& \sum_{k=1}^{n}\left|V_{i}\right| V_{k}|| Y_{i k} \mid \cos \left(\delta_{i}-\delta_{k}+\emptyset_{i k}\right)+P_{D G, i}=P_{D, i}+P_{L} \\
& \sum_{k=1}^{n}\left|V_{i}\right| V_{k}|| Y_{i k} \mid \sin \left(\delta_{i}-\delta_{k}+\emptyset_{i k}\right)=Q_{\overrightarrow{D, i}}+Q_{L} \\
& \sum_{k=1}^{n}\left|V_{i}\right| V_{k}|| Y_{i k} \mid \cos \left(\delta_{i}-\delta_{k}+\emptyset_{i k}\right)+P_{D G, i}-P_{D, i}-P_{L}=0 \\
& \sum_{k=1}^{n}\left|V_{i}\right| V_{k}|| Y_{i k} \mid \sin \left(\delta_{i}-\delta_{k}+\emptyset_{i k}\right)-Q_{\overrightarrow{D, i}}-Q_{L}=0
\end{aligned}
$$

\section{Methods}

\subsection{Grey Wolf Optimizations Methods}

Grey wolf belongs to the Candidate family they are mainly considered as apex predators, and it means that they are at the topmost of the food series. Grey wolves generally like to live in a collection. These classifications usually are 5-12. It is an incredibly harsh, community superiority hierarchy.

\subsection{The Aim, Design, and Setting of the Study}

Figure 2a shows the steps of the hierarchy are small from alpha $(\alpha)$ to omega $(\omega)$ search agents. All take the decisions regarding sleeping place, hunt, and waking time. The alpha $(\alpha)$ choice is dictated to the pack. Beta $(\beta)$ are supporting wolves that assist the $(\alpha)$ indecisiveness making and reinforces the $(\alpha)$ commands throughout.

Moreover, $(\beta)$ working such that response source for alpha $(\alpha)$, as well as the delta $(\delta)$ wolf's reportage to alpha and Beta. Moreover, omega $(\omega)$ is an assistant and to the lowest degree level of hierarchy [32].

The general assumption for mathematical modeling:

- The GWO in the algorithm for the social hierarchy, alpha $(\alpha)$, is said to be the best fit solution according to the Beta $(\beta)$ and delta $(\delta)$ the follow such as the second and third best-fit solutions for them respectively. Grey wolf optimization algorithm is guided by the three wolves, omega $(\omega)$ wolves follow $(\alpha),(\beta)$, and $(\delta)$ and the hunting (optimization).

- GWO first encircle prey after than the circling prey during hunting and follow to determine the encircling behavior is presented [32].

$$
\begin{aligned}
& \vec{K}=\left|\vec{B} \cdot \vec{Z}_{p}(t)-\vec{Z}(i t)\right| \\
& \vec{Z}(i t+1)=\vec{Z}_{p}(t)-\vec{D} \cdot \vec{K}
\end{aligned}
$$

where the current iteration, $\vec{Z}$ and $\vec{Z}_{p}$ the position vector of a grey wolf, and the prey respectively, the vector $\vec{B}$ and $\vec{D}$ indicate the coefficient vectors are calculated as follow,

$\vec{D}=2 \vec{d} \cdot \vec{r}_{1}-\vec{d}$

$\vec{B}=2 \cdot \vec{r}_{2}$

where $\vec{r}_{1}, \vec{r}_{2}$ are the random numbers between 0 and 1 . Component $\vec{d}$ is the linearly decreased from 2 to 0 over the course iterations.

$\vec{K}_{\alpha}=\left|\vec{B}_{1} \cdot \vec{Z}_{\alpha}(t)-\vec{Z}(i t)\right|$

$\vec{K}_{\beta}=\left|\vec{B}_{2} \cdot \vec{Z}_{\beta}(t)-\vec{Z}(i t)\right|$

$\vec{K}_{\delta}=\left|\vec{B}_{3} \cdot \vec{Z}_{\delta}(t)-\vec{Z}(i t)\right|$

$\vec{Z}_{1}=\vec{Z}_{\alpha}(t)-\vec{D}_{1} \cdot\left(\vec{K}_{\alpha}\right)$ 


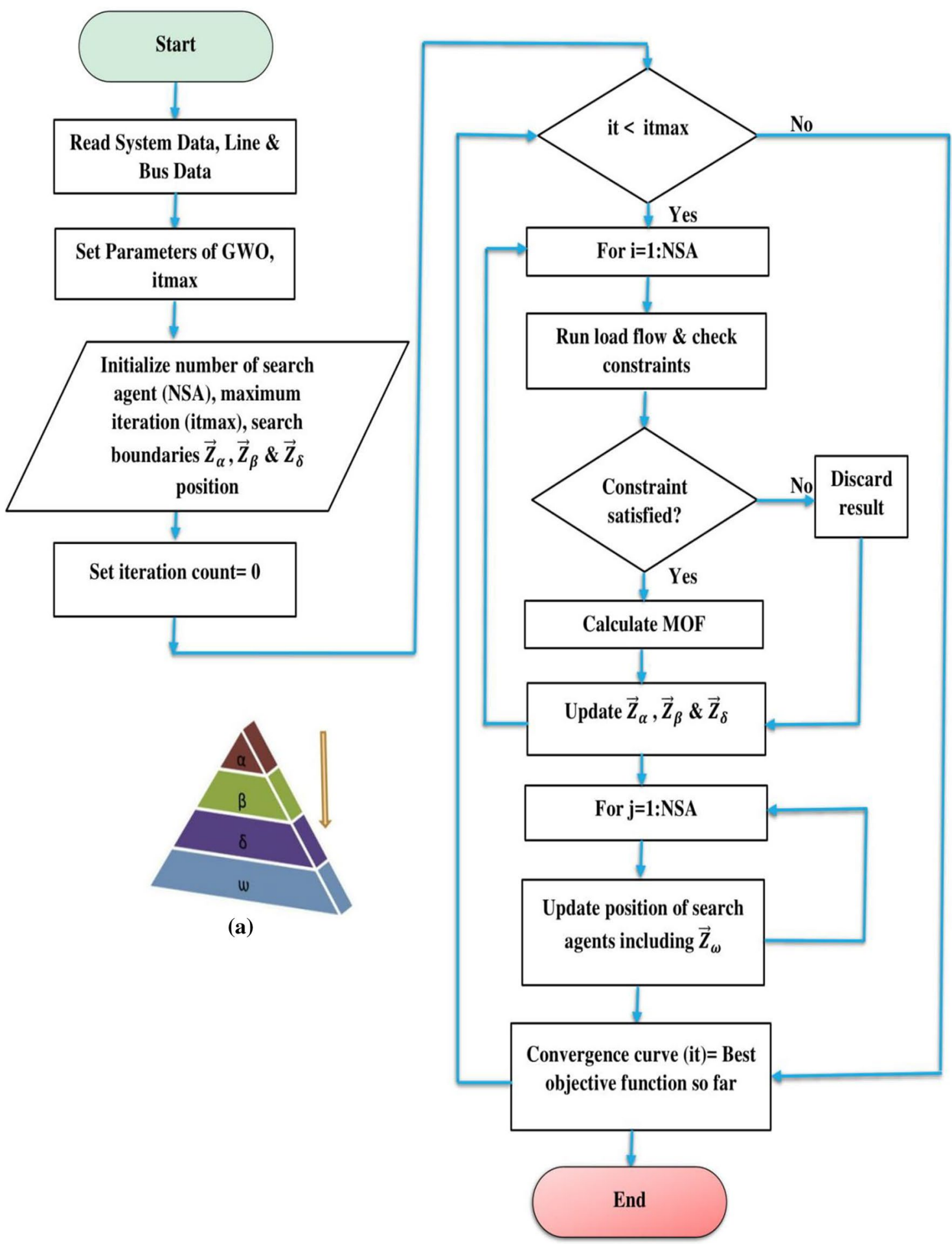

(b)

Fig. 2 a The level of the hierarchy from the top down. b The flow chart of proposed grey wolf optimization.

$\vec{Z}_{2}=\vec{Z}_{\beta}(t)-\vec{D}_{2} \cdot\left(\vec{K}_{\beta}\right)$

$\vec{Z}_{3}=\vec{Z}_{\delta}(t)-\vec{D}_{3} \cdot\left(\vec{K}_{\delta}\right)$ 
$\vec{Z}(i t+1)=\frac{\vec{Z}_{1}+\vec{Z}_{2}+\vec{Z}_{3}}{3}$

The GWO exploration and exploitation capability are appeared for by the prey for grey wolves find out and aggressively, [32].

\subsection{Execution of the GWO for Optimum DG Allotment}

Some steps execute GWO to get the optimum allocation (i.e., site and size). The method is explained by the flowchart Fig. 2b. The already to determine the maximal number of iterations, the dimension of the problem and the number of search agents are implemented [39].

\subsubsection{Step 1 -Starting}

The system study line data, load data calculate power flow and use the Newton-Raphson power flow method.

\subsubsection{Step 2-Positions of Grey Wolf Generation}

Search agent population is randomly generated by a GWO, and the initialized positions are $(\alpha),(\beta)$ and $(\delta)$ wolves, the setting for the parameter (size of DG, number, location, max. iteration ands population), after then every population for the objective function is to the calculation by the procedure of load flow.

\subsubsection{Step 3-Standard Explanations}

Every search agent constraint is investigated, and if the constraints are confirmed, after then the calculation of Multiobjective function (MOF) only just in case the infringement constraints the outcome is abandoned.

\subsubsection{Step 4-Select the Finest Location yet}

Compute the power loss and store the size of DG and decided the losses for the show that efficiency load flow and the update positions wolves, for $(\alpha),(\beta)$ and $(\delta)$, except the $(\omega)$ wolf after then the updating including $(\omega)$ wolf through the used to determine now the better solved.

\subsubsection{Step 5-Calculate the New Location of Search Agents}

To determine the newly search agents' positions and these operations are complete continuously.

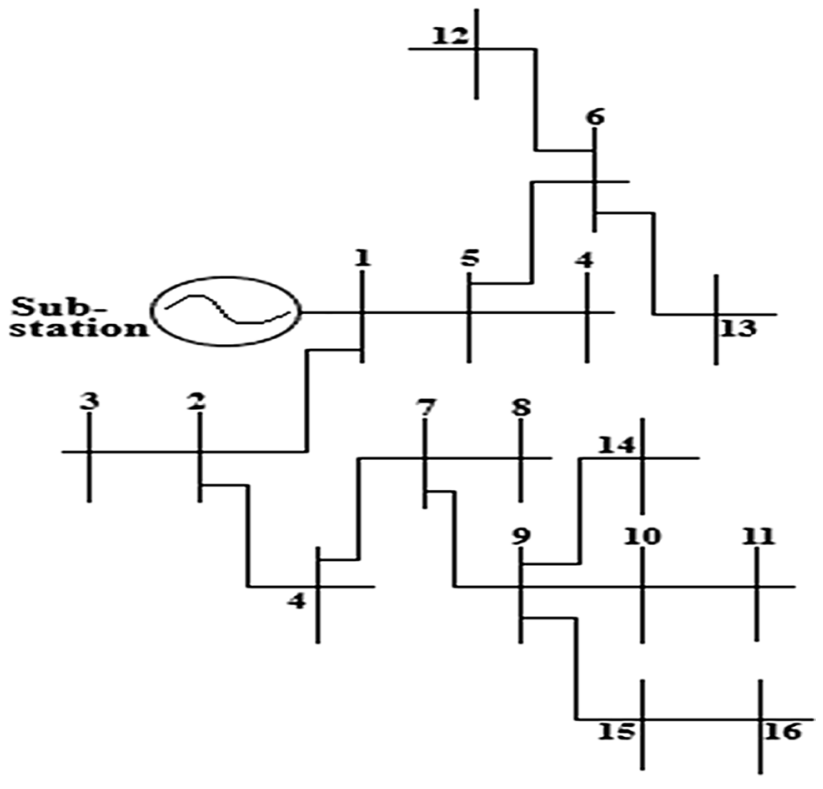

Fig. 3 Single line diagram of the IEEE-16 radial bus test system

\subsubsection{Step 6-Ending}

In this study, the standard has stopped the fixed maximal iterations, and the criteria are confirmed, after finishing the simulation and the optimal size of multiplier DG units and the confirmation on the whole particular distribution system of the constraints it will get it.

\section{IEEE-16 Bus System}

Figure 3 shows the IEEE 16-bus system of single line diagram for distribution system [36], and these system voltages is $12.66 \mathrm{kV}$, total system dynamic, reactive power loads is $1240.568 \mathrm{~kW}$ and $1265.478 \mathrm{kVAr}$. Including one slack bus 16 buses and 15 branches and load buses for these distribution systems respectively. The installation of real DG, reactive power losses with and without are $60.4031 \mathrm{~kW}$ and 55.3574 kVAr respectively in the 16-bus distribution system.

Table 1 shows the optimum location for the 16-bus system is 8 , the size of DG is 671.645 and the minimum before voltage installed of DG units is 0.9682 . The real, reactive power losses, minimized voltage later the position of dissimilar types of DG and further in case of without DG, with DG, with type $1 \mathrm{DG}$, with type $2 \mathrm{DG}$, with type $3 \mathrm{DG}$, with type DG at 0.9 pf and with type DG at unity pf. The minimized is more in case of with type 3 DG 0.9 pf when compared to other types of DG. The result shows that size of DG is maximum at lagging pf and as well as the compared size of DG to get at unity pf although the DG losses are reduction at lagging pf rather than at unity pf with DG, with due to 
Table 1 Results of IEEE-16 bus system

\begin{tabular}{llllllll}
\hline & Without DG & With DG & $\begin{array}{l}\text { With type 1 } \\
\text { DG }(\mathrm{kW})\end{array}$ & $\begin{array}{l}\text { With type 2 DG } \\
(\mathrm{kVAr})\end{array}$ & $\begin{array}{l}\text { With type 3 } \\
\text { DG }(\mathrm{kW})\end{array}$ & $\begin{array}{l}\text { With type D G 0.9 pf } \\
\text { lagging at (kVA) }\end{array}$ & $\begin{array}{l}\text { With type DG } \\
\text { unity pf at } \\
(\mathrm{kVA})\end{array}$ \\
\hline Location & - & 8 & 8 & 8 & 8 & 8 & 8 \\
DG size & - & 671.645 & 673.368 & 677.496 & 679.258 & 900.264 & 673.368 \\
TLP (kW) & 60.4031 & 44.8152 & 44.524 & 44.1524 & 44.2162 & 32.235 & 44.524 \\
TLQ (kVAr) & 55.3574 & 51.7013 & 43.3607 & 43.1245 & 43.0215 & 31.7012 & 43.3607 \\
$V_{\text {min }}$ & 0.9682 & 0.9532 & 0.9545 & 0.9531 & 0.9587 & 0.9594 & 0.9545 \\
\hline
\end{tabular}

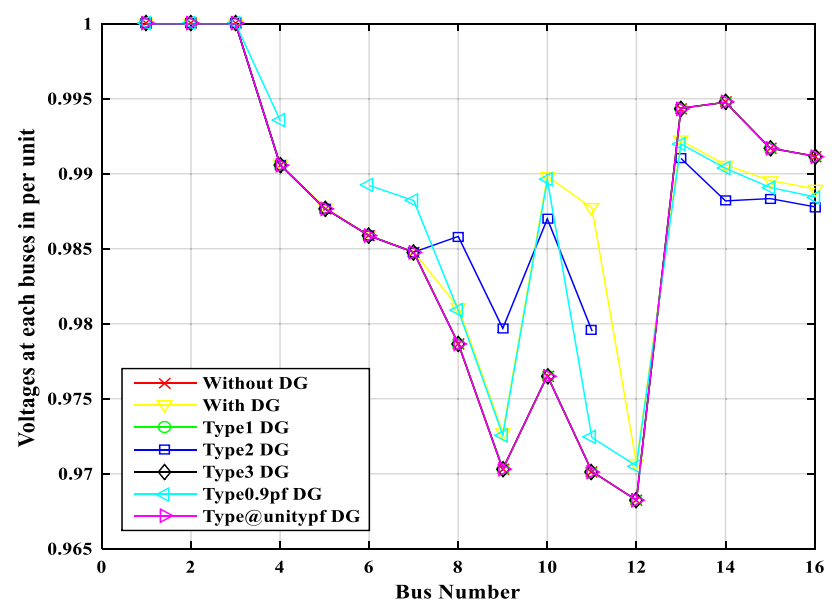

Fig. 4 Voltage profile IEEE-16 bus system

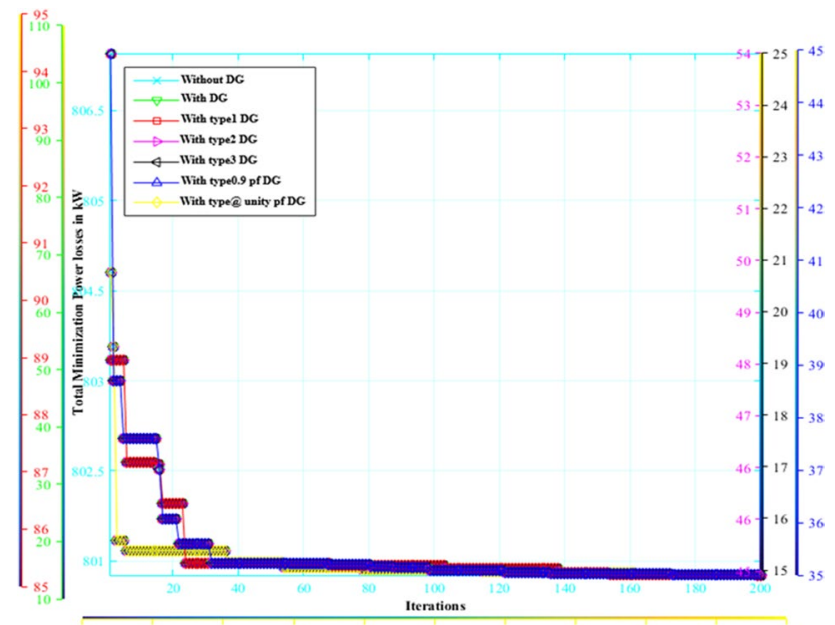

Fig. 5 Convergence characteristics of GWO IEEE-16 radial bus test system

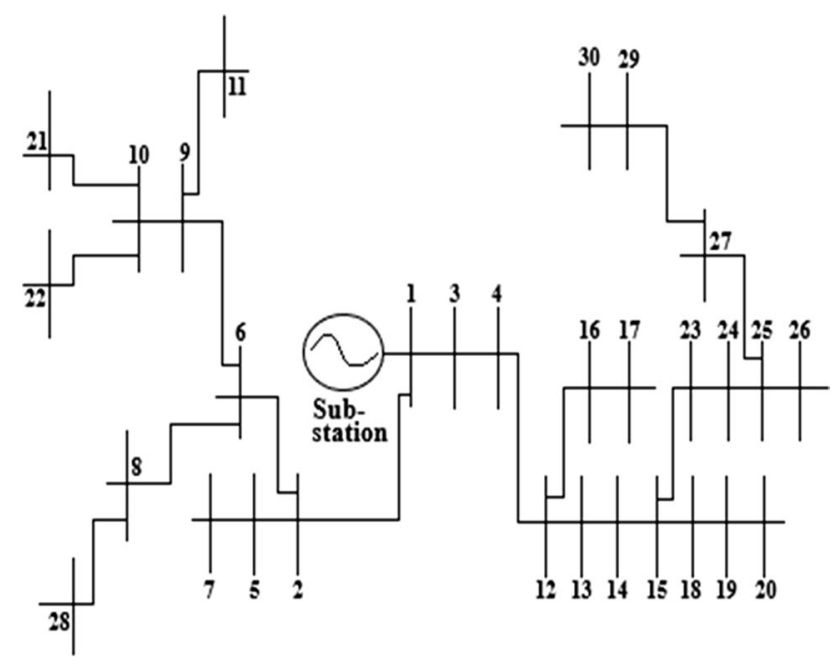

Fig. 6 Single Line Diagram of the IEEE-30 Radial Bus Test System

reactive power attainable local to the loads minimizing the reactive power obtainable from the substation.

Figure 4 shows the voltage profile of this system and size of DG is better at lagging pf and also voltage is a reduction to get the lagging pf compared as well as the DG at unity pf, so the necessary evaluate obtainable reactive power from the size of DG calculations and better voltage profile effects on the loss minimization. The result to acquire the observed of the reactive power is superior to the obtained as well as DG at unity pf.

Figure 5 shows the convergence characteristics of the GWO IEEE-16 radial bus test system consequently GWO algorithm are the total minimization power losses in $(\mathrm{kW})$ and 200 iterations. 
Table 2 Results of IEEE-30 bus system

\begin{tabular}{llllllll}
\hline & Without DG & With DG & $\begin{array}{l}\text { With type 1 } \\
\text { DG }(\mathrm{kW})\end{array}$ & $\begin{array}{l}\text { With type 2 DG } \\
(\mathrm{kVAr})\end{array}$ & $\begin{array}{l}\text { With type 3 DG } \\
(\mathrm{kW})\end{array}$ & $\begin{array}{l}\text { With type D G } \\
\text { 0.9pf lagging } \\
\text { at (kVA) }\end{array}$ & $\begin{array}{l}\text { With type DG } \\
\text { unity pf at (kVA) }\end{array}$ \\
\hline Location & & 27 & 27 & 27 & 27 & 27 & 27 \\
DG size & & 1530.08 & 1510.57 & 1220.11 & 1539.61 & 1915.24 & 1510.57 \\
TLP (kW) & 208.4592 & 118.452 & 120.652 & 150.852 & 152.25 & 76.524 & 120.652 \\
TLQ (kVAr) & 139.6552 & 86.785 & 87.201 & 101.212 & 89.120 & 56.120 & 87.201 \\
$V_{\text {min }}$ & 0.9610 & 0.9502 & 0.9051 & 0.9421 & 0.9215 & 0.9189 & 0.9051 \\
\hline
\end{tabular}

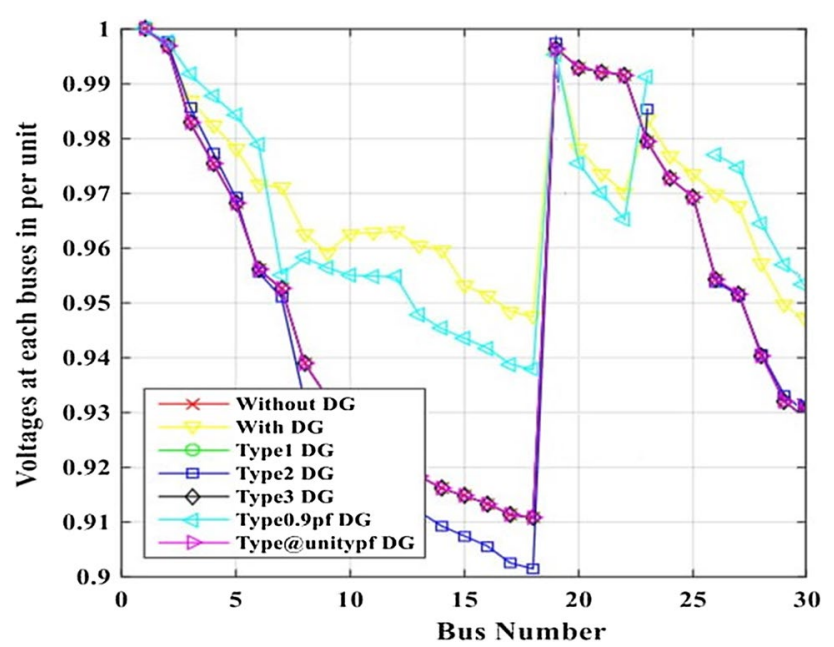

Fig. 7 Voltage profile IEEE-30 bus system

\section{IEEE-30 Bus System}

Figure 6 shows the IEEE 30-bus system of single line diagram for distribution system [36], and these system voltages is $12.66 \mathrm{kV}$, total system dynamic, reactive power loads are $3620.546 \mathrm{~kW}$ and $2200.784 \mathrm{kVAr}$. Including one slack bus 30 buses and 29 branches and load buses for these distribution systems respectively. The installation with and without real DG and reactive power losses are $208.4592 \mathrm{~kW}$ and 139.6552 kVAr in the 30-bus distribution system.

Table 2 shows the optimum location for the 30-bus system is 27 , the size of DG is 1530.08 and the minimum before voltage installed of DG units is 0.9111 . The real, reactive power losses, minimized voltage later the position of dissimilar types of DG and further in case of without DG, with DG, with type $1 \mathrm{DG}$, with type $2 \mathrm{DG}$, with type 3 DG, with type DG at 0.9 pf and with type DG at unity pf. The minimized is more in case of with type 3 DG $0.9 \mathrm{pf}$ when compared to other types of DG. The result shows that size of DG is maximum at lagging pf and as well as the compared size of DG to get at unity pf although the

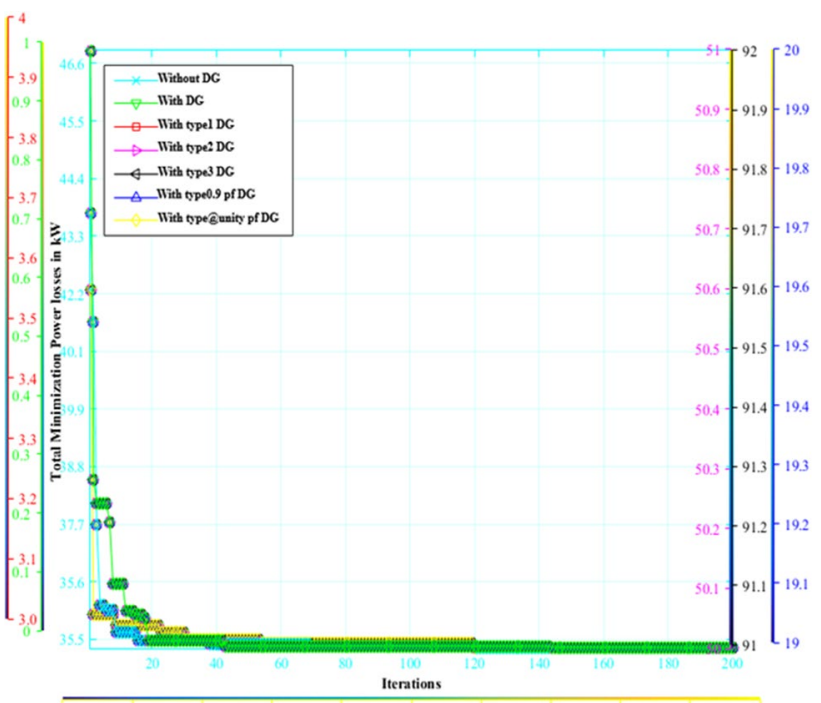

Fig. 8 Convergence characteristics of GWO IEEE-30 radial bus test system

Table 3 Comparison results of IEEE-16 and 30 bus system with DG at $0.9 \mathrm{pf}$

\begin{tabular}{lllll}
\hline & VSI method & $\begin{array}{l}\text { CPLS } \\
\text { method }\end{array}$ & NM method & $\begin{array}{l}\text { Proposed } \\
\text { method }\end{array}$ \\
\hline Location & 16 & 8 & 30 & 27 \\
DG size & 1200 & 2100 & 1950 & 1915.24 \\
TLP (kW) & 112.8 & 84.5 & 78.4 & 76.524 \\
TLQ (kVAr) & 77.4 & 62.1 & 58.9 & 56.120 \\
$V_{\text {min }}$ & 0.9378 & 0.9534 & 0.9391 & 0.9189 \\
\hline
\end{tabular}

DG losses are reduction at lagging pf rather than at unity pf with DG, with due to reactive power attainable local to the loads minimizing the reactive power obtainable from the substation.

Figure 7 shows the voltage profile of this system and size of DG is better at lagging pf and also voltage is a 
Table 4 Comparison results of IEEE-16 and 30 bus system with DG at unity pf

\begin{tabular}{lllll}
\hline & VSI method & $\begin{array}{l}\text { CPLS } \\
\text { method }\end{array}$ & NM method & $\begin{array}{l}\text { Proposed } \\
\text { method }\end{array}$ \\
\hline Location & 16 & 8 & 30 & 27 \\
DG size & 1000 & 1800 & 1550 & 1510.57 \\
TLP (kW) & 125.2 & 118.1 & 125.2 & 120.652 \\
TLQ (kVAr) & 89.3 & 82.90 & 89.3 & 87.201 \\
$V_{\text {min }}$ & 0.9275 & 0.943 & 0.927 & 0.9051 \\
\hline
\end{tabular}

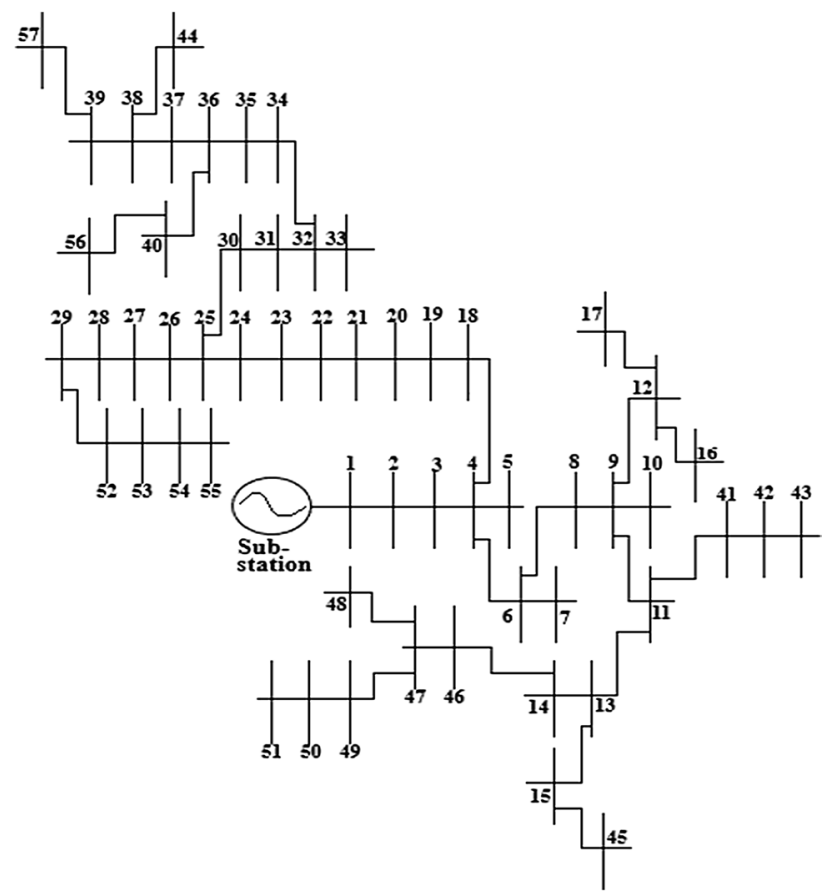

Fig. 9 Single line diagram of the IEEE-57 radial bus system

reduction to get the lagging pf compared as well as the DG at unity pf, so the necessary evaluate obtainable reactive power from the size of DG calculations and better voltage profile effects on the loss minimized, Fig. 8 shows the convergence characteristics of GWO IEEE-30 radial bus test system consequently GWO algorithm is the total minimization power losses in $(\mathrm{kW})$ and 200 iteration the result to acquire observer of the reactive power is superior to the obtained as well as DG at unity pf.

Table 3 shows the comparison results of the IEEE-16 and 30 bus system with DG at 0.9 pf. When comparing as well as VSI, CPLS and NM methods, it gives better results [35].

Table 4 shows the comparison results of the IEEE-16 and 30 bus system with DG at 0.9 pf. When comparing as well as VSI, CPLS and NM methods, it gives better results [35].

\section{IEEE-57 Bus System}

Figure 9 shows the IEEE 57-bus system of single line diagram for distribution system [36], and these system voltages is $12.66 \mathrm{kV}$, total system active, reactive power loads is $3802.190 \mathrm{~kW}$ and $2694.600 \mathrm{kVAr}$. Including one slack bus 57 buses and 56 branches and load buses for these distribution systems respectively. The installation with and without real DG and reactive power losses are $158.643 \mathrm{~kW}$ and $99.861 \mathrm{kVAr}$ in the 57-bus distribution system.

Table 5 shows the optimum location for the 57-bus system is 46 , the size of DG is 1278.66 and the minimum before voltage installed of DG units is 0.9510 . The real, reactive power losses, minimized voltage later the position of dissimilar types of DG and further in case of without DG, with DG, with type 1 DG, with type 2 DG, with type 3 DG, with type DG at 0.9 pf and with type DG at unity pf. The minimized is more in case of with type 3 DG $0.9 \mathrm{pf}$ when compared to other types of DG. The result shows that size of DG is maximum at lagging pf and as well as the compared size of DG to get at unity pf although the DG losses are reduction at lagging $p$ rather than at unity pf with DG, with due to reactive power attainable local to the loads minimizing the reactive power obtainable from the substation.

Figure 10 shows the voltage profile of these systems and size of DG is better at lagging pf and also voltage is

Table 5 Results of IEEE-57 bus system

\begin{tabular}{llllllll}
\hline & Without DG & With DG & $\begin{array}{l}\text { With type 1 } \\
\text { DG }(\mathrm{kW})\end{array}$ & $\begin{array}{l}\text { With type 2 DG } \\
(\mathrm{kVAr})\end{array}$ & $\begin{array}{l}\text { With type 3 } \\
\text { DG }(\mathrm{kW})\end{array}$ & $\begin{array}{l}\text { With type D G 0.9 pf } \\
\text { lagging at (kVA) }\end{array}$ & $\begin{array}{l}\text { With type DG } \\
\text { unity pf at } \\
(\mathrm{kVA})\end{array}$ \\
\hline Location & - & 46 & 46 & 46 & 46 & 46 & 46 \\
DG size & - & 1278.66 & 1267.31 & 729.80 & 1241.51 & 1651.31 & 1267.31 \\
TLP (kW) & 158.643 & 45.075 & 72.972 & 121.671 & 102.09 & 18.012 & 72.972 \\
TLQ (kVAr) & 99.861 & 28.771 & 16.513 & 27.864 & 75.014 & 8.51023 & 16.513 \\
$V_{\text {min }}$ & 0.9510 & 0.9445 & 0.9027 & 0.9326 & 0.9590 & 0.9127 & 0.9027 \\
\hline
\end{tabular}




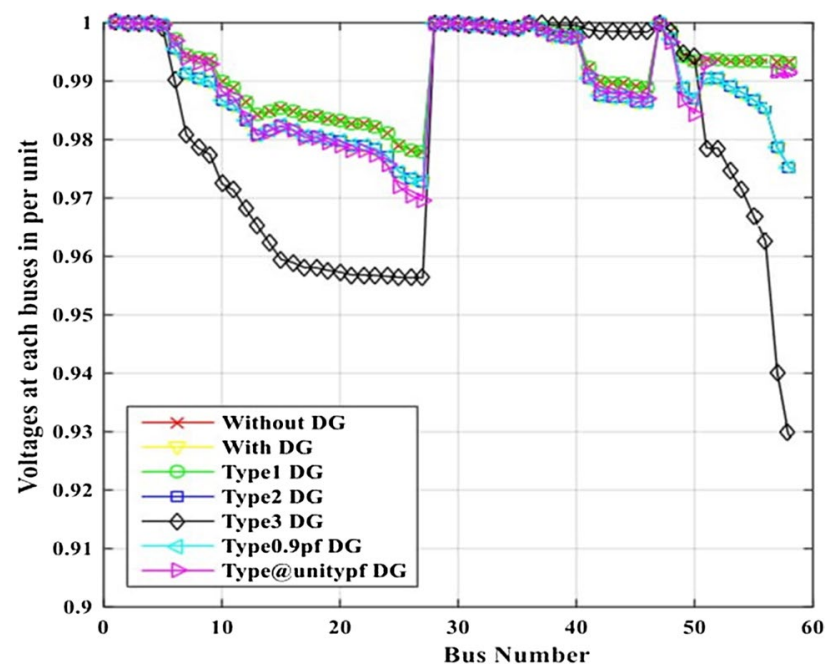

Fig. 10 Voltage profile IEEE-57 bus system

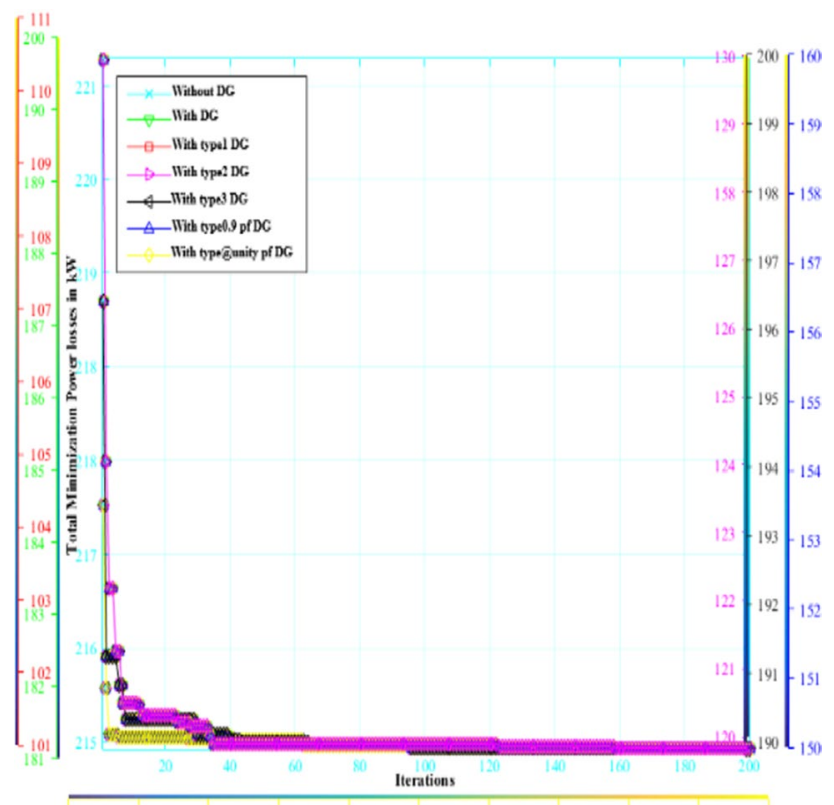

Fig. 11 Convergence characteristics of GWO IEEE-57 radial bus test system

Table 6 Comparison results of IEEE-16, 30 and 57 bus system with $\mathrm{DG}$ at $0.9 \mathrm{pf}$

\begin{tabular}{lllll}
\hline & VSI method & $\begin{array}{l}\text { CPLS } \\
\text { method }\end{array}$ & NM method & $\begin{array}{l}\text { Proposed } \\
\text { method }\end{array}$ \\
\hline Location & 16 & 8 & 30 & 46 \\
DG size & 1200 & 100 & 1950 & 651.31 \\
TLP (kW) & 112.8 & 84.5 & 78.4 & 18.012 \\
TLQ (kVAr) & 77.4 & 62.1 & 58.9 & 8.51023 \\
$V_{\text {min }}$ & 0.9378 & 0.9534 & 0.9391 & 0.9127 \\
\hline
\end{tabular}

Table 7 Comparison results of IEEE-16, 30 and 57 bus system with DG at unity pf

\begin{tabular}{lllll}
\hline & VSI method & $\begin{array}{l}\text { CPLS } \\
\text { method }\end{array}$ & NM method & $\begin{array}{l}\text { Proposed } \\
\text { method }\end{array}$ \\
\hline Location & 16 & 8 & 30 & 46 \\
DG size & 1000 & 1800 & 1550 & 1267.31 \\
TLP (kW) & 125.2 & 118.1 & 125.2 & 72.972 \\
TLQ (kVAr) & 89.3 & 82.90 & 89.3 & 16.513 \\
$V_{\text {min }}$ & 0.9275 & 0.943 & 0.927 & 0.9027 \\
\hline
\end{tabular}

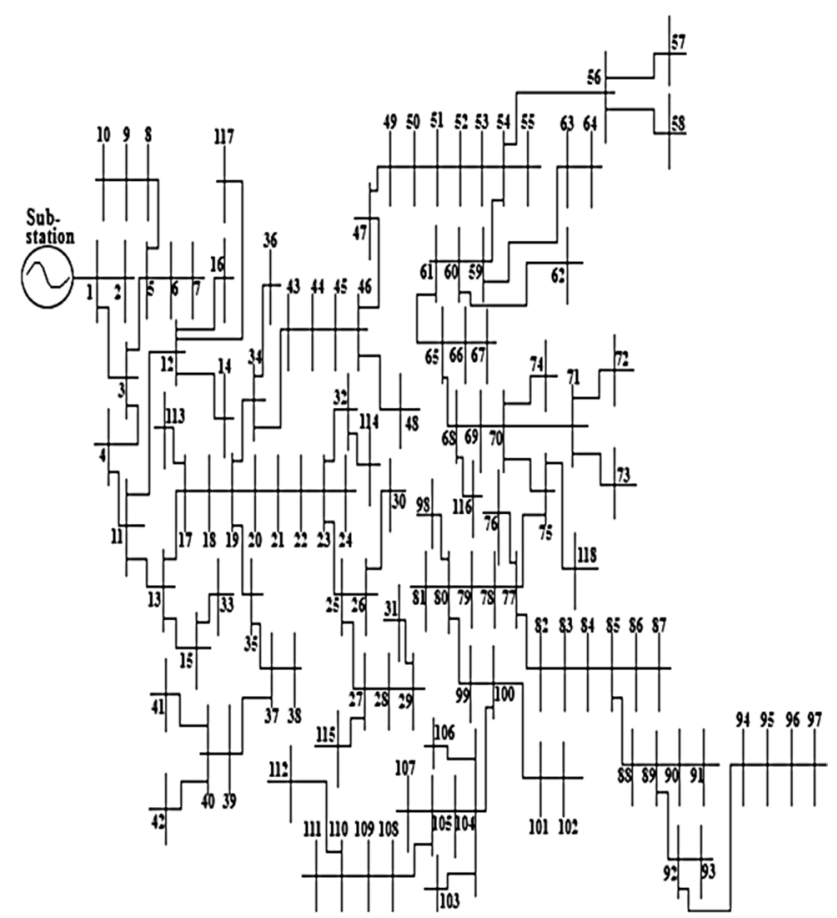

Fig. 12 Single line diagram of the IEEE-118 radial bus test system

a reduction to get the lagging pf compared as well as the DG at unity pf, so the necessary evaluate available reactive power from the size of DG calculations and better voltage profile effects on the loss minimization. The result to acquire the observed of the reactive power is superior to the obtained as well as DG at unity pf.

Figure 11 shows the convergence characteristics of the GWO IEEE-57 radial bus test system consequently GWO algorithm are the total minimization power losses in $(\mathrm{kW})$ and 200 iterations.

Table 6 shows the comparison results of the IEEE-16, 30 and 57 bus systems with DG at 0.9 pf. When comparing as well as VSI, CPLS and NM methods, it gives better results [35].

Table 7 shows the comparison results of the IEEE16,30 and 57 bus systems with DG at unity pf. When 
Table 8 Results of IEEE-118 bus system

\begin{tabular}{|c|c|c|c|c|c|c|c|}
\hline & Without DG & With DG & $\begin{array}{l}\text { With type } 1 \mathrm{DG} \\
(\mathrm{kW})\end{array}$ & $\begin{array}{l}\text { With type } 2 \\
\text { DG (kVAr) }\end{array}$ & $\begin{array}{l}\text { With type } 3 \text { DG } \\
(\mathrm{kW})\end{array}$ & $\begin{array}{l}\text { With type D G } 0.9 \mathrm{pf} \\
\text { lagging at (kVA) }\end{array}$ & $\begin{array}{l}\text { With type DG } \\
\text { unity pf at } \\
(\mathrm{kVA})\end{array}$ \\
\hline Location & $\longrightarrow$ & 113 & 113 & 113 & 113 & 113 & 113 \\
\hline DG size & $\longrightarrow$ & 2580.12 & 2704.01 & 2198.23 & 2650.54 & 3357.24 & 2704.57 \\
\hline TLP $(\mathrm{kW})$ & 1298.09 & 1328.64 & 1092.21 & 1156.045 & 1100.25 & 986.69 & 1092.21 \\
\hline TLQ (kVAr) & 976.215 & 840.14 & 862.69 & 899.55 & 845.48 & 805.12 & 862.69 \\
\hline$V_{\min }$ & 0.9271 & 0.9584 & 0.9685 & 0.9401 & 0.9715 & 0.9686 & 0.9982 \\
\hline
\end{tabular}

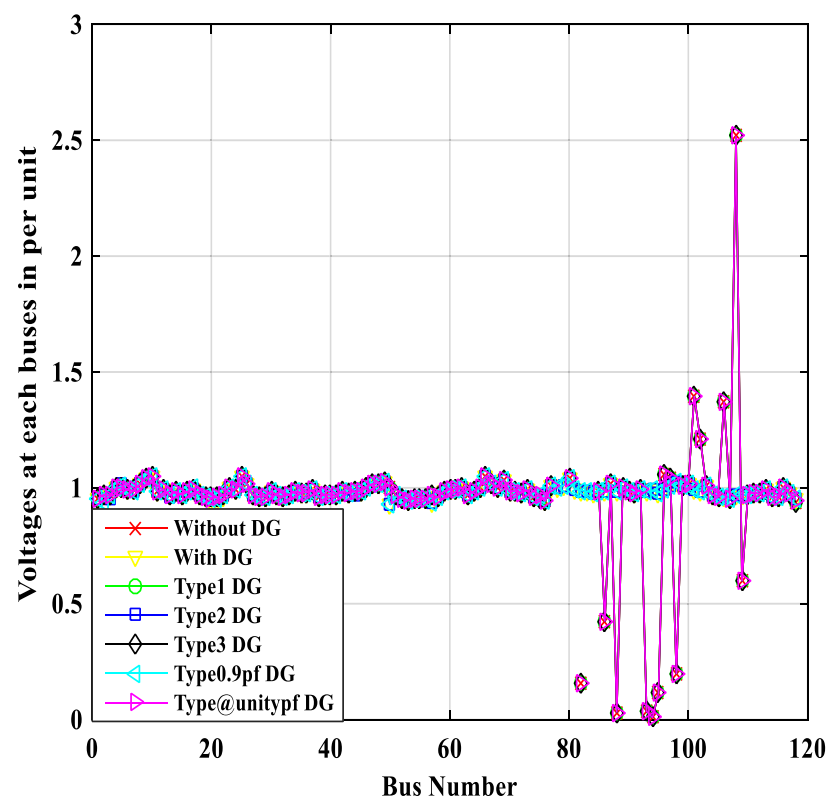

Fig. 13 Voltage profile IEEE-118 bus system

comparing as well as VSI, CPLS and NM methods, it gives better results [35].

\section{IEEE-118 Bus System}

Figure 12 shows the IEEE 118-bus system of single line diagram for distribution system [37], and these system voltages is $12.66 \mathrm{kV}$, total system active, reactive power loads is $199,785.683 \mathrm{~kW}$ and $115,431.015 \mathrm{kVAr}$. Including one slack bus 118 buses and 117 branches and load buses for these distribution systems respectively. The installation with and without real DG and reactive power losses are $1298.09 \mathrm{~kW}$ and $976.215 \mathrm{kVAr}$ in the 118-bus distribution system.

Table 8 shows the optimum location for the 118-bus system is 113 , the size of DG is 2580.12 and the minimum before voltage installed of DG units is 0.9271 . The real, reactive power losses, minimized voltage later the position

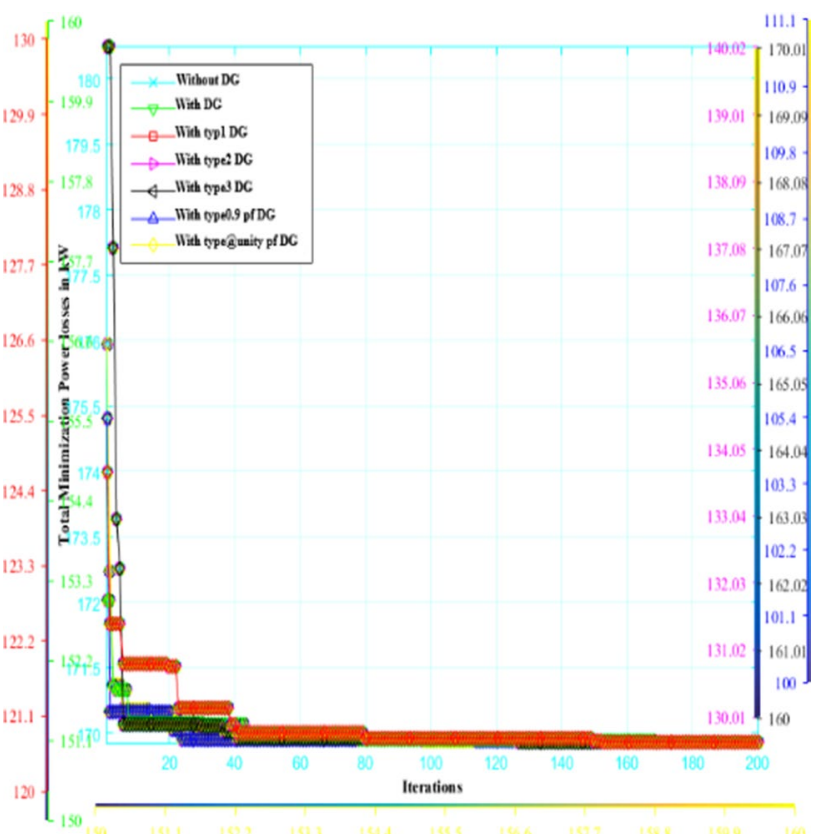

Fig. 14 Convergence characteristics of GWO IEEE-118 radial bus test system

Table 9 Comparison results of IEEE-16, 30, 57 and 118 bus system with DG at $0.9 \mathrm{pf}$

\begin{tabular}{lllll}
\hline & VSI method & $\begin{array}{l}\text { CPLS } \\
\text { method }\end{array}$ & NM method & $\begin{array}{l}\text { Proposed } \\
\text { method }\end{array}$ \\
\hline Location & 8 & 27 & 46 & 113 \\
DG size & 2100 & 1915.24 & 1651.31 & 3357.24 \\
TLP $(\mathrm{kW})$ & 84.5 & 76.524 & 18.012 & 986.69 \\
TLQ (kVAr) & 62.1 & 56.120 & 8.51023 & 805.12 \\
$V_{\text {min }}$ & 0.9534 & 0.9189 & 0.9127 & 0.9686 \\
\hline
\end{tabular}

of dissimilar types of DG and further in case of without DG, with DG, with type 1 DG, with type 2 DG, with type 3 DG, with type DG at 0.9 pf and with type DG at unity pf. The minimized is more in case of with type 3 DG $0.9 \mathrm{pf}$ 
Table 10 Comparison results of IEEE-16, 30, 57 and 118 bus system with DG at unity pf

\begin{tabular}{lllll}
\hline & VSI method & $\begin{array}{l}\text { CPLS } \\
\text { method }\end{array}$ & NM method & $\begin{array}{l}\text { Proposed } \\
\text { method }\end{array}$ \\
\hline Location & 8 & 27 & 46 & 113 \\
DG size & 1800 & 1510.57 & 1267.31 & 2704.57 \\
TLP (kW) & 118.1 & 120.652 & 72.972 & 1092.46 \\
TLQ (kVAr) & 82.90 & 87.201 & 16.513 & 862.69 \\
$V_{\text {min }}$ & 0.943 & 0.9051 & 0.9027 & 0.9982 \\
\hline
\end{tabular}

when compared to other types of DG. The result shows that size of DG is maximum at lagging pf and as well as the compared size of DG to get at unity pf although the DG losses are reduction at lagging pf rather than at unity pf with DG, with due to reactive power attainable local to the loads minimizing the reactive power obtainable from the substation.

Figure 13 shows the voltage profile of these systems and size of DG is better at lagging pf and also voltage is a reduction to get the lagging pf compared as well as the DG at unity $\mathrm{pf}$, so the necessary evaluate obtainable reactive power from the size of DG calculations and better voltage profile effects on the loss minimization. The result to acquire the observed of the reactive power is superior to the obtained as well as DG at unity pf.

Figure 14 shows the convergence characteristics of the GWO IEEE-118 radial bus test system; consequently, the GWO algorithm is the total minimization power losses in $(\mathrm{kW})$ and 200 iterations.

Table 9 shows the comparison results of the IEEE-16, 30, 57 and 118 bus systems with DG at 0.9 pf. When comparing as well as VSI, CPLS and NM methods, it gives better results [35].

Table 10 shows the comparison results of the IEEE-16, 30,57 and 118 bus systems with DG at 0.9 pf. When comparing as well as VSI, CPLS and NM methods, it gives better results [35].

\section{Percentage Loss Reductions}

Figure 15 shows the percentage loss reductions along with all types of DG units for IEEE-16, 30, 57, and 118 bus test systems respectively. From pie chart without DG, with DG, with type $1 \mathrm{DG}$, with type $2 \mathrm{DG}$, with type $3 \mathrm{DG}$, with type DG at 0.9 pf and with type DG at unity pf lagging gives more loss reductions.

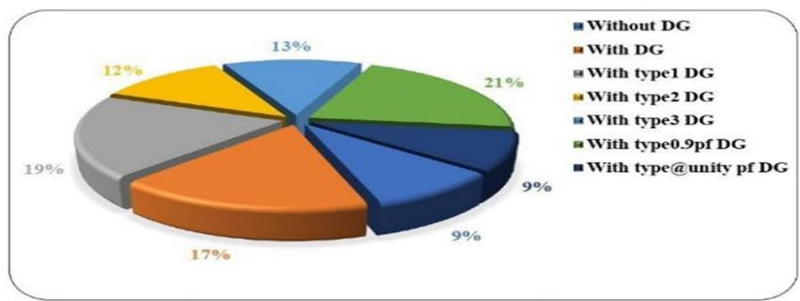

(a)

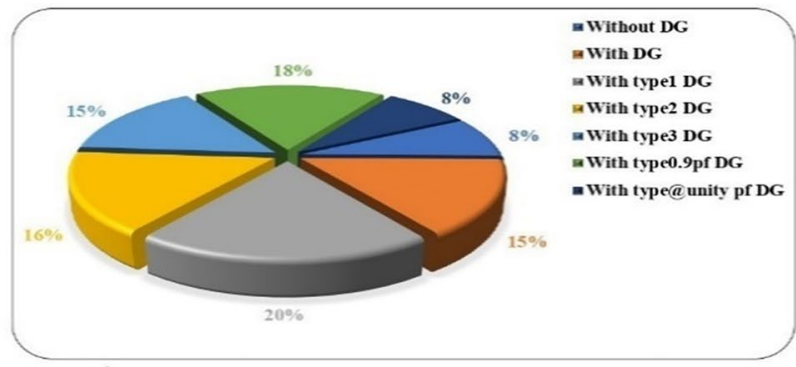

(b)

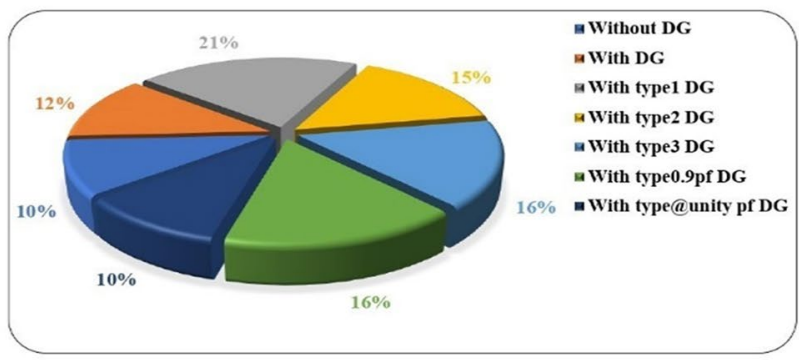

(c)

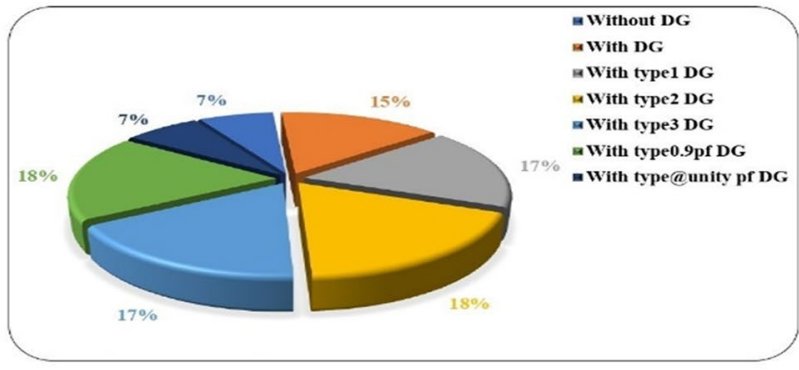

(d)

Fig. 15 a The percentage loss reductions IEEE-16 bus test system. b The percentage loss reductions IEEE-30 bus test system. c The percentage loss reductions IEEE-57 bus test system. d The percentage loss reductions IEEE-118 bus test system

\section{Convergence Characteristics Curves}

Figure 16 is the convergence characteristics curves of IEEE$16,30,57$, and 118 bus test systems respectively. All these convergence characteristics curves GWO algorithm is converged rapidly and the objective function and 200 iterations. 


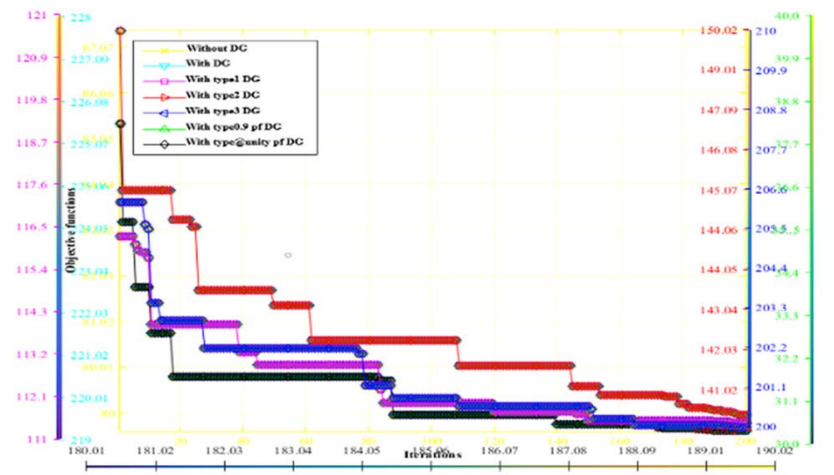

(a)

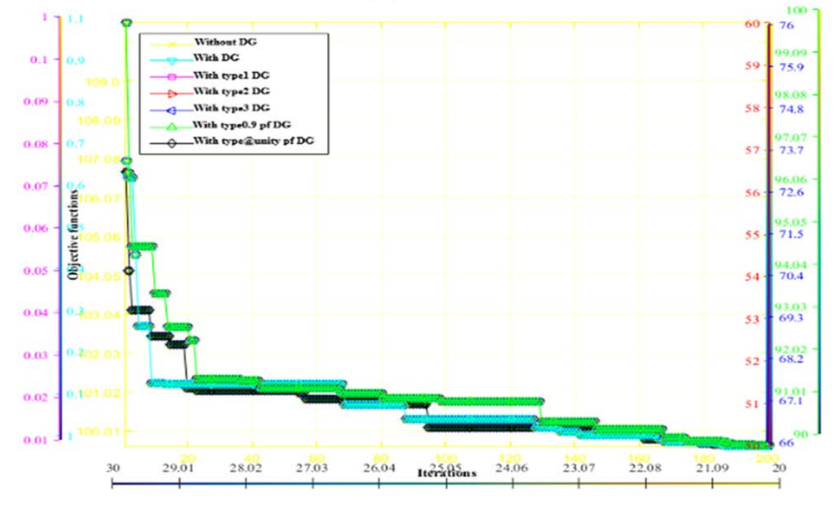

(b)

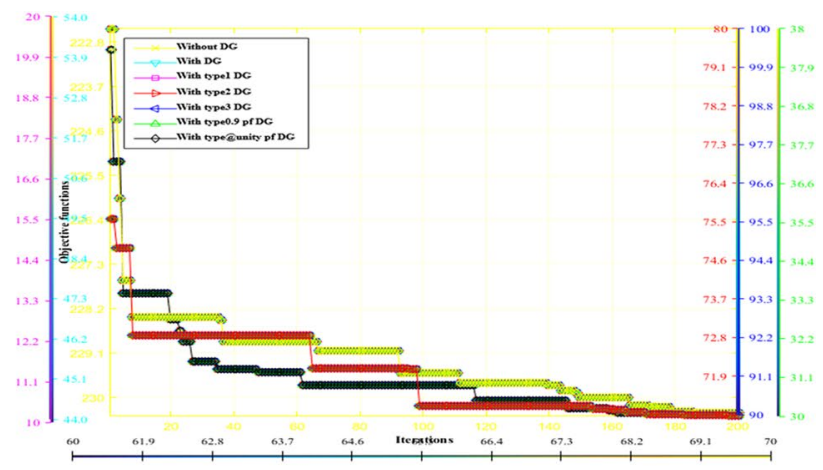

(c)

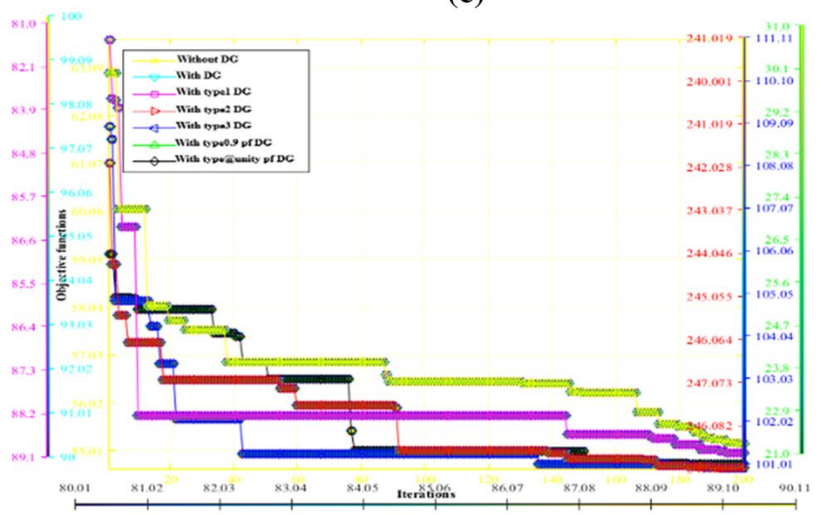

(d)

Fig. 16 a The convergence characteristics curves of IEEE-16 bus test system. b The convergence characteristics curves of IEEE-30 bus test system. $\mathbf{c}$ The convergence characteristics curves of IEEE- 57 bus test system. $\mathbf{d}$ The convergence characteristics curves of IEEE-118 bus test system

Consequently, the GWO algorithm is practical, reliable and able to treatment mixed-integer nonlinear optimization problems [38].

\section{Conclusions}

A novel nature encourages in GWO algorithm modeled based on the objective function is used to analyzing the optimum location, size of DG, it's the minimization of system power loss and gets a better voltage profile. The procedure is standard on IEEE-16, 30, 57 and 118 radial bus test distribution systems as well as the considering multiplier DG superior consequence and gets to the GWO. When compared as well as another method and the simulation outcome show that the all-inclusive effect the DG unit voltage profile is affirmative and proportionate minimization of power losses in the distribution system is attained. Since it generates both the real and reactive power and able to interjected the better results had been attained without DG, with DG, with type 1 DG, with type 2 DG, with type 3 DG, with type DG at 0.9 pf and with type DG at unity pf.
Acknowledgements The authors are thankful to the College of Electrical Engineering, Yuquan Campus Zhejiang University Hangzhou, China and the Institute of Electrical Engineering, Yanshan University Qinhuangdao, China for providing necessary facilities to conduct this research. This work is supported by the "Science and Technology program of Zhejiang Huayun Electric Power Engineering Design \& Consultation Company Limited" (2019C1D09P01).

Open Access This article is licensed under a Creative Commons Attribution 4.0 International License, which permits use, sharing, adaptation, distribution and reproduction in any medium or format, as long as you give appropriate credit to the original author(s) and the source, provide a link to the Creative Commons licence, and indicate if changes were made. The images or other third party material in this article are included in the article's Creative Commons licence, unless indicated otherwise in a credit line to the material. If material is not included in the article's Creative Commons licence and your intended use is not permitted by statutory regulation or exceeds the permitted use, you will need to obtain permission directly from the copyright holder. To view a copy of this licence, visit http://creativecommons.org/licenses/by/4.0/.

\section{References}

1. Kalambe S, Agnihotri G (2014) Loss minimization techniques used in distribution network: bibliographical survey. Renew Sustain Energy Rev 29:184-200 
2. Ackerman T, Andersson G, Soder L (2001) Distribution generation: a definition. Electric Power Syst Res 57:195-204

3. Sultana B, Mustafa MW, Sultana U, Bhatti AR (2016) Review on reliability improvement and power loss reduction in distribution system via network reconfiguration. Renew Sustain Energy Rev 66:297-310

4. Sanjay R, Jayabarathi T, Raghunathan T, Ramesh V, Mithulananthan N (2017) Optimal allocation of distributed generation using hybrid grey wolf optimizer. IEEE Access 5:14807-14818

5. Martín García JA, Gil Mena AJ (2013) Optimal distributed generation location and size using a modified teaching-learning based optimization algorithm. Int J Electric Power Energy Syst 50:65-75

6. Kansal S, Kumar V, Tyagi B (2013) Optimal placement of different type of dg sources in distribution networks. Int J Electric Power Energy Syst 53:752-760

7. Karimyan P, Gharehpetian GB, Abedi M, Gavili A (2014) Long term scheduling for optimal allocation and sizing of Dg unit considering load variations and DG type. Int J Electric Power Energy Syst 54:277-287

8. Guerriche KR, Bouktir T (2015) Optimal allocation and sizing of distributed generation with particle swarm optimization algorithm for loss reduction. Revue des Sciences et de la Technologie 6:59-69

9. Duong Quoc H, Mithulananthan N (2013) Multiple distributed generator placement in primary distribution networks for loss reduction. IEEE Trans Ind Electron 60:1700-1708

10. Mahmoud K, Yorino N, Ahmed A (2016) Optimal distributed generation allocation in distribution systems for loss minimization. IEEE Trans Power Syst 31:960-969

11. Jamian J, Mustafa M, Mokhlis H, Baharudin M, Abdilahi A (2014) Gravitational search algorithm for optimal distributed generation operation in autonomous network. Arab J Sci Eng 39:7183-7188

12. Khatod DK, Pant V, Sharma J (2013) Evolutionary programming based on optimal placement of renewable distributed generators. IEEE Trans Power Syst 28:683-695

13. Hung DQ, Mithulananthan N, Lee KY (2014) Optimal placement of dispatchable and nondispatchable renewable DG units in distribution networks for minimizing energy loss. Int J Elect Power Energy Syst 55:179-186

14. Nasri A, Hamedani Golshan M, Mortaza Saghaian Nejad S (2014) Optimal planning of dispatchable and none-dispatchable distributed generation units for minimizing distribution system's energy loss using particle swarm optimization. Int Trans Elect Energy Syst 24:504-519

15. Sultana S, Roy PK (2015) Oppositional krill herd algorithm for optimal location of distributed generator in radial distribution system. Int J Elect Power Energy Syst 73:182-191

16. Moravej Z, Akhlaghi A (2013) A novel approach based on cuckoo search for Dg allocation in distribution network. Int J Elect Power Energy Syst 44:672-679

17. Hung DQ, Mithulananthan N (2014) Loss reduction and loadability enhancement with DG: a dual-index analytical approach. Appl Energy 115:233-241

18. Aman M, Jasmon G, Bakar A, Mokhlis H (2014) A new approach for optimum simultaneous multi-Dg distributed generation units placement and sizing based on maximization of system loadability using hpso (hybrid particle swarm optimization) algorithm. Energy 66:202-215

19. Nguyen Cong H, Mithulananthan N, Bansal RC (2013) Location and sizing of distributed generation units for loadabilty enhancement in primary feeder. IEEE Syst J 7:797-806

20. Al-Abri RS, El-Saadany EF, Atwa YM (2013) Optimal placement and sizing method to improve the voltage stability margin in a distribution system using distributed generation. IEEE Trans Power Syst 28:326-334

21. Adaryani MR, Karami A (2013) Artificial bee colony algorithm for solving multi-objective optimal power flow problem. Int $\mathbf{J}$ Elect Power Energy Syst 53:219-230. https://doi.org/10.1016/j. ijepes.2013.04.021

22. Duman S, Güvenc U, Sönmez Y, Yörükeren N (2012) Optimal power flow using gravitational search algorithm. Energy Convers Manage 59:86-95. https://doi.org/10.1016/j.encon man.2012.02.024

23. Yang X-S, Gandomi AH (2012) Bat algorithm: a novel approach for global engineering optimization. Eng Comput 29(5):464-483. https://doi.org/10.1108/02644401211235834

24. Mistry KD, Roy R (Jan. 2014) 'Enhancement of loading capacity of distribution system through distributed generator placement considering techno-economic benefits with load growth'. Int J Elect Power Energy Syst 54:505-515

25. Yang X-S (2012) Flower pollination algorithm for global optimization. In: unconventional computation and natural computation, vol 7445. Springer, Berlin, pp 240-249. https://doi. org/10.1007/978-3-642-32894-727

26. García JAM, Mena AJG (2013) 'Optimal distributed generation location and size using modified teaching-learning-based optimization algorithm'. Int J Elect Power Energy Syst 50:65-75

27. El-Fergany A (Jan. 2015) 'Optimal allocation of multi-type distributed generators using backtracking search optimization algorithm'. Int J Elect Power Energy Syst 64:1197-1205

28. Gandomi AH, Alavi AH (Dec. 2015) 'Krill herd: A new bioinspired optimization algorithm'. Commun Nonlinear Sci Numer Simul 17(12):4831-4845

29. Mirjalili S (2015) Moth-flame optimization algorithm: a novel nature-inspired heuristic paradigm. Knowl-Based Syst 89:228249. https://doi.org/10.1016/j.knosys.2015.07.006

30. Mijalili S (2016) SCA: a sine cosine algorithm for solving optimization problems. Knowl-Based Syst 96:120-133

31. Askarzadeh A (2016) A novel metaheuristic method for solving constrained engineering optimization problems: crow search algorithm. Comp Struct 169:1-12

32. Mirjalili S, Mirjalili SM, Lewis A (2014) Grey wolf optimizer. Adv Eng Softw 69:46-61

33. Hadi Saadat (2002) Power system analysis 2nd edn. TMH Publication.

34. Wadhwa CL (2010) Electrical power system, 6th edn. New Age International Publication, Chennai

35. Murty VVSN, Kumar A (2014) Mesh distribution system analysis in the presence of distributed generation with a time-varying load model. Int J Elect Power Energy Syst 62:836-854. https://doi. org/10.1016/j.ijepes.2014.05.034

36. Baran ME, Wu FF (1989) Network reconfiguration in distribution systems for loss reduction and load balancing. IEEE Trans Power Deliver 4(2):1401-1407

37. Zhang D, Fu Z, Zhang L (2007) An improved is an algorithm for loss-minimum reconfiguration in large-scale distribution systems. Elect Power Syst Res 77:685-694. https://doi.org/10.1016/j. epsr.2006.06.005

38. Reddy P, Reddy VC, Manohar T (2018) Ant Lion optimization algorithm for optimal sizing of renewable energy resources for loss reduction in distribution systems. J Elect Syst Inf Technol. https://doi.org/10.1016/j.jesit.2017.06.001

39. Sultana U, Khairuddin AB, Mokhtar AS, Zareen N, Sultana B (2016) Grey wolf optimizer-based placement and sizing of multiple distributed generation in the distribution system. Energy. https ://doi.org/10.1016/j.2016.05.128

Publisher's Note Springer Nature remains neutral with regard to jurisdictional claims in published maps and institutional affiliations 


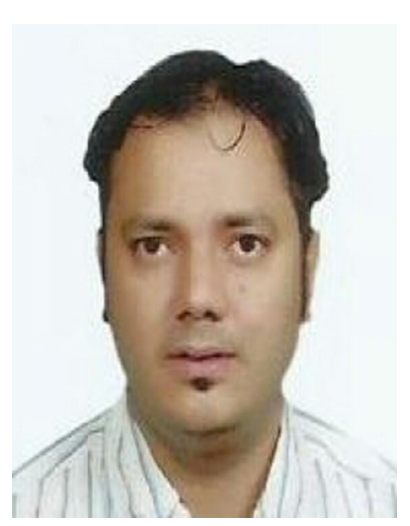

Renewable Energy Integration.
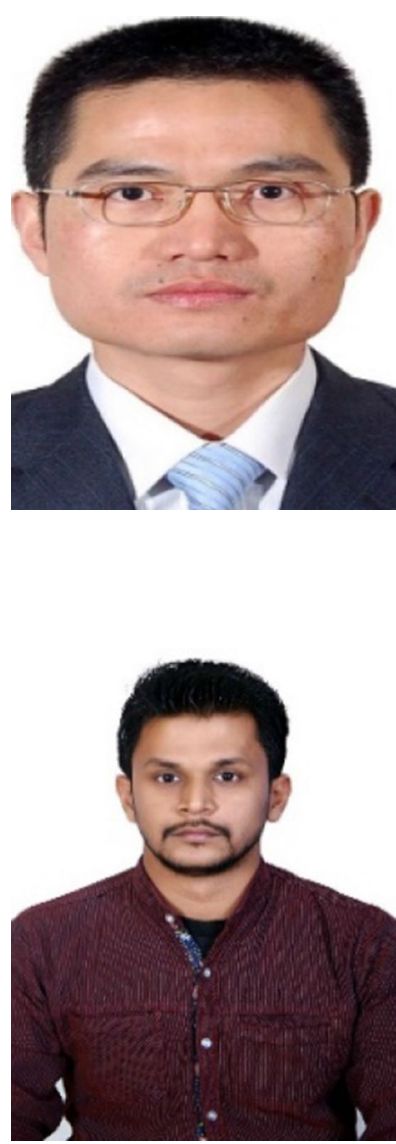

Muhammad Mohsin Ansari
Muhammad Suhail Shaikh received the Bachelor's of Electronics Engineering (BE), from Hamdard University Karachi, Pakistan, and Master of Engineering in Electrical Engineering (ME), from Indus University, Karachi Pakistan in 2013 and 2016, respectively and now pursuing Doctoral degree at Institute of Electrical, Engineering, Yanshan University, Qinhuangdao, China. His current research interests are Power System Analysis including Fault Analysis, Control \& Renewable Energy.
Chuangxin Guo received the B.Sc., M.Sc., and Ph.D. degrees in Electrical Engineering from Huazhong University of Science and Technology, China, in 1992, 1994, and 1997, respectively. He is currently a Professor and Vice Dean in the College of Electrical Engineering, Zhejiang University. received the Bachelor's in ElecUni Technology from the Ned Technology Karachi, Pakistan and Master's of Science in Electrical from the Indus University Karachi, Pakistan in 2011 and 2016. He is currently pursuing a Ph.D. degree in Electrical EngiIt Zhejiang University, Hangzhou, China. His current research areas of interest include Pystem Analysis, Distribution Generation, Distribution Networks, Smart Grids, \&

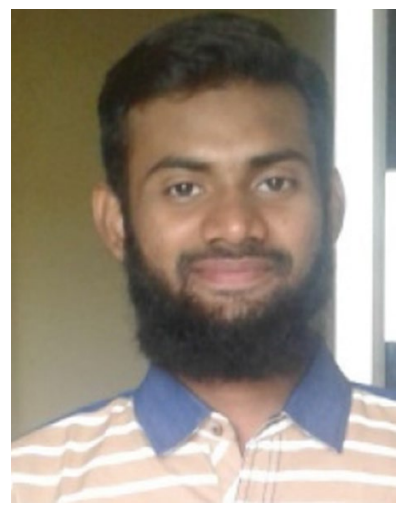

Nitish Chopra received the Bach-

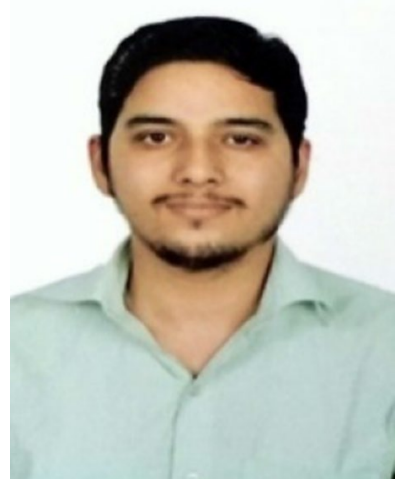
elor's in Electrical \& Electronic Engineering and Masters of Technology in Electrical Engineering from I.K. Gujral Punjab Technical University, India in 2013 and 2015. He is currently an Assistant Professor in the Electrical Engineering Department at St Soldier Group of Institutions, Jalandhar. His current research areas of interest include Power System Optimization, Metaheuristic Algorithms, Microgrids \& Renewable Energy.

Inzamamul Haq received the Bachelor's of Electrical Engineering (BE), from the National College of Engineering in 2016. He's currently working in Spiro Technology Tirunelveli, India as a Research Associate Software Engineer. His currents research Power Electronics, Power System Analysis.
Lingbing Shen received a Bachelor of Science in Electrical Engineering (BS). He's currently working in Zhejiang Huayun Electric Power Engineering Design \& Consultation Company Limited Hangzhou, China as an Electrical Engineer. His currents research Power System, Distribution Generations, Renewable Energy System. 